\title{
Os Novos Espaços do Investimento Português
}

\author{
Mario Guillermo Gomez Olivares* \\ Cezar Augusto Miranda Guedes** \\ Luiz António Casimiro Santos ${ }^{* * *}$
}

\begin{abstract}
Resumo: Neste artigo explora-se os investimentos portugueses no Brasil, os quais tiveram uma natureza característica da época da globalização, muito ligada à compra de empresas proporcionada pela abertura ao capital privado. Procuramos mostrar que os investimentos são o resultado das características de competitividade da economia portuguesa, num contexto onde investimentos portugueses se inscrevem numa lógica ibérica, ocupando um espaço caracterizado pelas afinidades linguística, culturais e afectiva, o que permite um diálogo fluido, incluindo o plano político. Verifica-se também que a recepção mais favorável dos investimentos portugueses e do IDE em geral por parte dos estados de A. L resulta de uma visão diferente sobre o desenvolvimento, onde o investimento estrangeiro é visto como uma alavanca ao processo de crescimento económico, enquadrando-se num modelo de abertura ao exterior, de incentivo às exportações, de modernização económica e tecnológica.
\end{abstract}

Palavras-chave: Modelo de desenvolvimento; Macroeconomia; Política económica; Desenvolvimento; Política monetária; Investimento estrangeiro.

\section{Introdução}

$\mathrm{O}$ acento na competitividade internacional tornou-se fundamental para a sobrevivência das empresas no sentido de conquistar novos espaços e proceder a uma integração vertical do território económico, num contexto de desenvolvimento de uma nova ordem internacional, utilizando as vantagens da difusão das inovações em tecnologias de informação e produção. Na posse de vantagens competitivas as empresas se internacionalizam na busca de novos espaços que possam gerar um novo ciclo de acumulação baseado na integração dos novos territórios económicos.

As Empresas Transnacionais (ET's) são, na sua grande maioria, as protagonistas mais relevantes desta nova dinâmica de territorialização em curso, o que obriga a por ênfase na análise baseada nas vantagens competitivas geradas pelas empresas em novos espaços e na sua área de acção específicas, e menos no país como um todo. Esta extraordinária expansão à escala mundial deve-se à actividade de mais de 60000 empresas transnacionais com cerca de 800000 filiais no estrangeiro. Os principais pontos de origem e destino destes investimentos são, respectivamente, as ET's do núcleo orgânico capitalista e novas zonas emergentes. Esta expansão incide de modo decisivo no comércio mundial: uma terceira parte do comércio mundial de bens e serviços não factoriais corresponde a operações de conglomerados transnacionais realizadas entre as casas matrizes e as filiais (Sela:2002).

Os investimentos estrangeiros directos são hoje uma das âncoras do novo modelo de desenvolvimento que começou a operar na América Latina desde os anos noventa do século passado, marcado por

\footnotetext{
'Instiluto Superior de Economia e Gestāo, Universidade Técnica de Lisboa.

"* Instituto de Ciências Humanas e Sociais, Universidade Federal Rural do Rio de Janeiro.

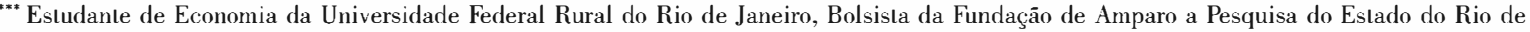
Janeiro (FAPERJ).
} 
uma tendência mundial de desenvolvimento capitalista, caracterizado pela mobilização de capitais no espaço globalizado, pela internacionalização da economia mundial e das empresas à escala global, que acaba por integrar a economia latino-americana de modo acelerado, em pleno acordo com a vontade dos governos regionais.

Os motivos que levam à internacionalização por parte das empresas portuguesas têm uma lógica própria e encontram terreno propício no processo de abertura económica caracterizado pela nova modalidade de desenvolvimento condensada na ideia do Consenso de Washington, que recomenda de modo taxativo a abertura económica, as privatizações das empresas estatais, a permissão da venda de activos importantes da área privada, pela abertura e participação em áreas consagradas tradicionalmente ao Estado, como as infra-estruturas e os serviços públicos.

Considerando as perspectivas do novo modelo, o Investimento Directo Estrangeiro é uma variável fundamental a considerar, no sentido que a abertura ao exterior preconizada no menu recomendado de desenvolvimento capitalista a partir do centro, reflecte os interesses das multinacionais que ampliam a sua presença não apenas obtendo lucros, mas integrando a zona geográfica no processo de internacionalização, procurando aumentar a sua competitividade à escala global.

Não se trata de expandir apenas as empresas num sentido tradicional, com o objectivo de projectos que consideram a relevância do aumento da capacidade produtiva, mas de aproveitar uma nova modalidade de desenvolvimento, uma nova urbanidade social que gerou a industrialização globalizada, que apoiam e lucram com o crescente sector exportador, o qual se tem transformado num elemento de dinamismo importante do crescimento económico e de procura de mais serviços. Não se procura apenas construir empresas para explorar matérias-primas, ou servir de base para acções de exportação à escala continental, na lógica do que é a tradicional exportação de capitais a esferas lucrativas ou de prolongamento do comércio com lucros de eficiência. Os investimentos intro- duzem-se em áreas de grande relevo para o desenvolvimento, como as energias, as redes de água e saneamento, infra-estruturas de comunicações, os portos e redes rodoviárias. É justamente isto que dá uma característica particular aos investimentos estrangeiros em relação ao passado: a formação de um espaço vasto de relações sociais, culturais e geográficas, que se estendem ao económico, configurando um espaço heterogéneo de relações sincrónicas.

Salienta-se também que a forma de ingresso desses capitais passa, predominantemente, pela compra de activos de empresas (privadas ou estatais) já existentes, ou seja, pela modalidade de fusões e aquisições, onde o destino dos investimentos portugueses privilegia o sector dos serviços. Portugal procura ter uma participação significativa nesse processo. As suas empresas mais significativas elevaram consideravelmente seus investimentos no exterior, alterando a condição de importador líquido de capital que possuíam até então. Desde a óptica portuguesa, além do aumento no volume dos fluxos de investimento directo no exterior, confirma-se uma alteração na destinação preponderante dos investimentos lusitanos nos anos de 1990, sendo Brasil e Espanha destinos preferenciais, destacando-se ainda a participação da Holanda nos últimos anos.

Nesse sentido, esses fluxos possuem mútua importância para Portugal ${ }^{1}$, pelo que torna-se propósito desta pesquisa analisar os fluxos de investimento directo originado pelas empresas portuguesas para o Brasil no período de 1996 a 2007, destacando-se o sector de telecomunicações, representado pela Portugal Telecom (PT), e o sector de geração e distribuição de energia eléctrica, representado pela Energias de Portugal (EDP). Temos que considerar a relevância do caso brasileiro numa óptica de longo prazo, visto que o stock de IDE (se comparado ao produto interno bruto) é de $25,4 \%$, superior aos países do grupo denominado BRIC (Brasil, Rússia, Índia, China), totalizando U\$ 201,2 bilhões em 2006. Para os demais países, os números são: Rússia (17,3\%) com U\$ 132,5; Índia (5,8\%) com $\mathrm{U} \$ 45,3$ e China $(14,3 \%)$ com U\$317,0 bilhões (UNCTAD: 2007).

\footnotetext{
${ }^{1}$ Observa-se ainda uma relevância dos Países Africanos de Língua Oficial Portuguesa (PALOP), como destino para os investimentos portugueses, ressaltando a preponderância de Angola.
} 


\section{Internacionalização e novos velhos territórios}

Os países latino-americanos, em geral, e do Mercosul e associados, experimentaram um processo de inserção internacional das suas economias, seja como lugares de recepção e aplicação de investimentos internacionais ou como epicentros de recepção desses investimentos na direcção de todo o continente. Este tipo de intervenção económica, vista como crucial para o desenvolvimento económico dos países, a par dum conjunto necessário de condições, tais como a liberalização dos espaços e privatização das empresas, tem possibilitado uma alteração significativa no modo de funcionamento dessas economias, instaurando uma lógica capitalista privada, uma maior especialização dessas economias no comércio, na modernização tecnológica das suas industrias exportadoras e dos seus serviços, assim como acentuada modernização, em boa parte da agropecuária e das indústrias processadoras de bebidas e alimentos, e outros sectores importantes.

$\mathrm{O}$ estudo actual das economias revela-nos transformações de fundo: foi instaurada uma economia de espaço privada, o que tem obrigado aos diferentes países a alterações nas suas estruturas institucionais, mecanismos legais e de regulação, adequação dos espaços e do seu enquadramento social, o que se tem revelado muitas vezes insuficiente, pouco apropriado e, por vezes, desajustado, de acordo com a visão que se tenha dessa transformação.

Nesse sentido, ao discutir os investimentos directos estrangeiros, consideramos esta variedade de investimentos como um processo maioritariamente de aquisição e de fusão de empresas, comparativamente com o processo mais tradicional de investimentos das multinacionais tradicionais em fábricas ou em novos produtos, levando a transformações qualitativamente diferentes, fruto da inserção de empresas, de integração de espaços e de ressurgimento presencial dos antigos colonizadores.

O caso dos investimentos portugueses, seguindo a tendência geral, tem a particularidade de se dirigir a áreas de serviços produtivos vinculados ao espaço interno e à própria região. Aqui, consideramos anteriormente e, em particular, as motivações das empresas em processos de investimentos, procurando explicar porque realizam os seus investimentos, em que zonas geográficas, quantificar os montantes invertidos à sua distribuição sectorial, qual é a influência dos elementos de comunidade linguística e de cultura comum (Olivares e Guedes: 2003); se esclarecem também os factores que tornam em parte semelhante o critério português com o espanhol, ao que chamamos de lógica ibérica, a que enuncia o propósito estratégico da Espanha de ser uma potência de porte médio a partir duma zona geográfica vasta, mas com a intenção de valorizar a sua posição no terreno europeu, seja no plano económico como também no político. Nesse sentido se argumenta que, para além do seu peso relativo, o perfil e a estratégia seguida pelas empresas portuguesas segue um caminho semelhante ao dos espanhóis (Guedes e Olivares: 2003).

É importante a referência ao quadro mais geral da economia portuguesa, à sua inserção na Europa e na economia mundial, tendo em vista evidenciar, por um lado, a correlação entre a natureza dos investimentos no estrangeiro e, por outro, os seus limites e possibilidades em termos da sua competitividade.

$\mathrm{O}$ crescimento dos investimentos nos anos noventa obedece a uma situação única, que é o processo de privatizações, que permitiu a aquisição de empresas de serviços em áreas financeiras, infra-estruturas, telecomunicações, resultado da decisão politica de emagrecer o Estado na sua qualidade de Estado empresário, procurando uma lógica de desenvolvimento na base da iniciativa privada e da regulação, em que se privilegia o espaço, de mudar a politica de produção de bens públicos, permitindo a licitação, a cedência temporária de activos a favor de empresas privadas, o que tem implicado, de facto, ceder posições às empresas estrangeiras em posição de substituir o Estado, o que explica que pouco menos de um terço dos investimentos tenha representado criação de empresas (greenfields), o que explica também a escassa contribuição em termos de criação de emprego.

No caso português, a maioria dos investimentos das empresas portuguesas estão concentrados no Brasil que, conjuntamente com a minimização dos custos de comunicação em razão da língua comum, possui outros factores de atracção, os quais vão desde o clima favorável aos investimentos, ao ciclo de privatizações em particular, até às características estruturais positivas, como o tamanho da economia e das possibilidades de crescimento, o que permite às empresas portuguesas maior escala na procura de espaços, permitindo-lhes também consolidar a 
sua estratégia competitiva, com vista à respectiva política europeia (Guedes e Olivares: 2003). A partir dos critérios de especialização característicos, procura-se articular os factores internos e externos que conferem ao Investimento Directo Estrangeiro das empresas portuguesas uma estratégia mais selectiva dos espaços, embora cooperativa ou subordinado com outros agentes ibéricos.

Embora o crescimento económico tenha aumentado relativamente à década anterior, e apesar de existirem e de sentirem dificuldades estruturais, dificuldades na articulação da política económica com os objectivos do desenvolvimento económico e social, o governo do Brasil tem vindo a propor a conjugação das procuras sociais com a nova estrutura económica que emerge com o modelo económico, respeitando o novo motor de crescimento baseado na inserção internacional que privilegia o sector exportador, permite a mobilidade do capital, o que obriga a manter uma relação estável entre preços internos e externos, pelo que, contraditoriamente, sacrifica a procura interna aos equilíbrios da balança de pagamento e das necessidades de investimentos estrangeiros em esferas vitais da existência humana, tais como educação, saúde e segurança social, onde o crescimento depende da estabilidade financeira, o que se consegue com equilíbrios de produção e emprego vinculados a uma crónica dívida externa.

Uma década de investimentos deve ser vista também como um processo duplo de integração na economia mundial e, ao mesmo tempo, de concentração e centralização do capital, pelo que os critérios de investimentos seguirão uma lógica que privilegie os grandes espaços, a redução dos custos, as condições institucionais, as oportunidades de cooperação importantes, a estabilidade política, todos elementos que consolidem e ampliem o processo de globalização liderado pelas transnacionais.

Nesse sentido, o curso dos investimentos continuará forte no Brasil, que reúne as condições de tornar atractivos os investimentos nas áreas de infra-estrutura, logística e geração de energia, respondendo aos desafios do "apagão logístico" colocado como uma ameaça em razão do crescimento dos últimos anos. Há também a possibilidade da compra em bolsa de grandes empresas privadas. Embora a avaliação do processo de desenvolvimento da última década seja cuidadoso e reservado, como se de um paciente em recuperação se tratasse, tudo aponta para que se mantenha a terapêutica da macroeconomia que contenha a inflação e o gasto do governo, controle os salários a um nível baixo e feche os olhos ao panorama da distribuição do rendimento; por outro lado, mantenha a abertura económica, facilitando o movimento dos capitais e os processos de compra e fusão de empresas, apoie as exportações como eixo fundamental do desenvolvimento e do crescimento económico.

A retórica da sustentabilidade do crescimento que elimine as dificuldades do passado e que levou quase ao colapso das economias latino-americanas e, em particular, o Brasil, produto do excesso de dívida externa, tem-se transformado na crença de que a economia de espaços universais criará o marco propicio e óptimo para um clima de investimentos estrangeiros que catapulte essas economias a ritmos de crescimento que lhes permitam superar o diferencial de desenvolvimento que as separa das economia desenvolvidas, que em grande medida concentram o grosso dos investimentos do comércio, e que integram os ramos industriais das nossas economias que passam a controlar segundo uma lógica de hegemonia económica, colocando o problema de realojar investimentos segundo os seus critérios de competitividade, como ensina o exemplo da industria maquiladora mexicana que é realojada na China.

A deslocação de investimentos segundo critérios de espaços com mão-de-obra mais barata, a aproximação a áreas de maior crescimento económico ou das zonas exclusivas da China e da Índia, unido a uma formação da mão-de-obra subsidiada com políticas de Estado, não deve ser um critério de permissividade aos investimentos. De facto, os investimentos estrangeiros devem ser destinados a espaços dinâmicos de longo prazo, com expressão na balança de pagamentos ou no desenvolvimento de infra-estruturas tecnológicas estratégicas. Os países desenvolvidos privilegiam os investimentos de maior potencial tecnológico nas suas próprias áreas, onde existe estabilidade política, recursos humanos amplos e competitividade comercial, o poder de compra é elevado, como expressão da riqueza acumulada capitalista, uma leitura que resulta do cenário, onde a maior parte dos investimentos irá concentrar-se em zonas que unem os critérios que determinam o investimento numa perspectiva de consolidação dos investimentos feitos na década anterior. 
Os câmbios institucionais, uma sorte de segunda vaga de reformas, parece ser a opção de governos regionais, ao privatizar novos sectores onde os investimentos privados estrangeiros possam encontrar esferas de aplicação com elevado retorno, o que é uma preocupação central dos investimentos realizados até agora, embora, como mostra o caso do Brasil, as empresas dos países desenvolvidos continuarão a investir na região, contribuindo para prosseguir o tipo de investimentos realizado na ultima década, com principal incidência na mineração e produtos energéticos, na indústria alimentar e bebidas, de serviços produtivos e lazer, e em menor grau no sector industrial.

Para avançar na direcção de um Estado regulador e promotor dos investimentos e da competência, o Brasil tem, no governo de Lula da Silva, aperfeiçoado os seus marcos reguladores e modernizado as entidades encarregadas da regulação naquelas indústrias com características monopólicas; mas precisa avançar na defesa dos direitos do consumidor e dos particulares; fortalecer a institucionalidade encarregada de velar pela competência dos espaços; modernizar e moralizar o poder judicial, dotando-o das capacidades para resolver conflitos próprios de economias de espaço privado. Isto requer voltar a pensar o papel do Estado numa economia de espaço público-privado, em particular como provedor de bens e serviços (Estado empresário) e o modo como o seu accionar pode distorcer a estrutura dos incentivos e castigos com que operam os agentes económicos. Igualmente, é necessário estudar a forma como se administram os recursos públicos, em particular para determinar as causas e consequências da ineficiência dos serviços públicos e a corrupção, amplamente radicada na região.
Depois de uma década de investimentos, é necessário colocar a questão de como continuará este processo, tomando em consideração que desde 1995 há um novo e considerável aumento dos investimentos na região, a maior parte produto da recuperação que se observou na economia mundial, dos próprios países europeus e EEUU, mas adicionando China, Índia que procuram ter acesso a espaços de matérias-primas e produtos energéticos, provocando o que se chamou no Brasil de "efeito China".

Os determinantes concretos do IDE são explicados pondo maior ou menor ênfase em alguns dos factores considerados como relevantes para a internacionalização das empresas; um conjunto de autores tais como Vernon e Hymer colocam acento na tecnologia, outros, como Caves, dão relevo ao diferencial das taxas de lucro. Horst prefere explicar o IDE pela capacidade de gestão e de marketing, Rainelli propõe a internacionalização da produção, as vantagens de propriedade (para a saída), locacionais (para a atracção).

De acordo com Dunning (1977), um autor muito considerado, o Investimento Directo Estrangeiro insere-se na lógica da internacionalização da produção, juntamente com o comércio exterior e as relações contratuais. O Investimento Directo Estrangeiro caracteriza-se pelo deslocamento de uma empresa de origem não-residente para um país, por meio da instalação de uma nova estrutura produtiva pertencente a esta empresa estrangeira, ou ainda pelo controle efectivo do capital de uma empresa já instalada, via operação de fusão ou aquisição ${ }^{2}$. Tendo em consideração a Balança de Pagamentos, mais especificamente a conta financeira, o investimento directo diferencia-se ainda dos investimentos

\footnotetext{
${ }^{2}$ Esta internacionalização da produção ocorre quando os residentes de um país acedem a bens e serviços com origem em não-residentes. Desse modo, o comércio exterior, forma mais antiga de internacionalização, se caracteriza pela produção de uma mercadoria em seu país de origem e sua exportação para um ou mais países. As relações contratuais, caracterizadas pelas franquias, assistências técnicas, licenças, royalties e outras, ocorrem quando uma empresa não-residente transfere para residentes activos, como a tecnologia do produto ou processo, capacidade gerencial, organizacional ou mercadológica, sob a protecção de contratos.

Analisando informações estatísticas oriundas do Banco de Portugal e do Gabinete de Estratégia e Estudo do Ministério de Economia e Inovação de Portugal (GEE), acerca dos fluxos de investimento direto de Portugal no exterior, aliadas as informações obtidas no sítio da Agência para o Investimento e Comércio Externo de Portugal (AICEP), procurou-se evidenciar o aumento do volume total desses fluxos e a alteração na destinação preponderante dos investimentos Portugueses, tendo Brasil e Espanha como principais destinos.

Fundamentando-se nos dados estatísticos do Banco de Portugal, verificamos a destinação do IDE português por sector de actividade, tendo como referência a Classificação de Actividades Económicas (CAE) Revisão 2.1, que por sua vez é baseada na International Standard Industrial Classification of All Economic Activities (ISIC) da Divisão de Estatísticas das Nações Unidas, o que possibilita uma comparabilidade internacional. Com isso objectivou-se constatar que os investimentos são, em sua maioria, destinados ao sector de serviços.

Baseado nos trabalhos do Departamento de Prospectiva e Planeamento do Ministério de Finanças de Portugal (DPP) fez-se uma análise conjuntural das empresas portuguesas internacionalizadas no Brasil.

Por fim, apoiado no Ranking das 1000 maiores empresas e dos 200 maiores grupos, em 2006, feito pela Revista Valor Económico, e em pesquisa nas páginas electrónicos das empresas, procurou-se estabelecer um ranking, através da receita líquida, das empresas com capital português internacionalizadas no Brasil com a finalidade de traçar um perfil sectorial dos investimentos. Visto que empresas importantes não estão incluídas no ranking do Valor Econômico, procurou-se identificá-las e apresenta-las por sector de actividade. Nesse sentido, é apresentado um histórico de cada empresa, ressaltando sua formação e sua internacionalização no Brasil.
} 
de carteira, ou de portfólio, que não são orientados para o controle operacional da empresa receptora do capital externo. De acordo com o Fundo Monetário Internacional (FMI) e a Organization for Economic Co-operation and Development (OCDE), o investimento estrangeiro é considerado directo quando detém uma participação no capital de, no mínimo, $10 \%$, podendo exercer influência sobre a gestão da empresa receptora (OCDE: 1995). Nesse sentido, o IDE é uma forma de investimento que denota um interesse duradouro numa empresa cuja exploração ocorre noutro país que não o do investidor ${ }^{3}$.

$\mathrm{O}$ advento das novas tecnologias de informação e comunicação (TICs) e, consequentemente, as redes de informação, possibilitaram a diminuição relativa das grandes distâncias geográficas, acelerando o processo de globalização. Essas novas TICs tiveram grande influência em vários níveis institucionais e foram determinantes para a mudança do foco de análise da internacionalização.

No nível produtivo, a difusão simultânea das técnicas de produção e a homogeneização das estratégias e métodos organizacionais desqualificam a teoria de Vernon para o ciclo de vida das técnicas e produtos, que diz que num primeiro estágio essas técnicas e produtos são desenvolvidos nos países centrais e, somente quando se esgotam seus ciclos de acumulação, são levados, num segundo estágio, aos países em desenvolvimento. Ambos os estádios se unem na procura da homogeneização do sistema produtivo, com base em técnicas e produtos divulgados e padronizados à escala mundial (Silva: 2005). As relações comerciais, por sua vez, são agilizadas, proporcionando a difusão não somente dos produtos mas também dos hábitos e costumes de um determinado país, fazendo com que esses produtos percam, gradualmente, o vínculo com o país de origem.

O dinamismo do espaço financeiro é considerado o exemplo mais visível da introdução das novas TICs. A unificação dos espaços num sistema simultâneo, o aumento na velocidade de circulação dos recursos entre pessoas, instituições e países, o espaço de capitais como alternativa de financiamento, findando a hegemonia dos bancos como gerado- res de empréstimos, entre outros fenómenos, são características da inserção dessas novas tecnologias que, aliadas à quebra nos anos setenta do sistema monetário baseado no dólar, tiveram influência na elevação da liquidez internacional.

Todo esse contexto proporcionou às Empresas Transnacionais (ETs) a superação dos limites geográficos na procura de maiores lucros e vantagens concorrenciais, expandindo-se pelo mundo, adquirindo grande poder económico e político e tornando-se as protagonistas do IDE. Com o auxílio das TICs, que agem sobre a mobilidade dos factores de produção, uma matriz de uma determinada transnacional pode controlar as suas filiais e subsidiárias em qualquer ponto do globo, além de ter amplo acesso às redes de informação da sua cadeia produtiva. Os efeitos da tecnologia da informação permitiram a transnacionalização das empresas e reorganizar as cadeias produtivas (Silva: 2005). Adicionalmente, o Estado deixa de actuar como promotor do desenvolvimento, entregando ao capital privado às suas actividades económicas produtivas, voltando-se às falhas de espaço e à desregulação da economia, embora a desregulamentação dos espaços esteja dificultando o estabelecimento de políticas fiscais, monetárias e cambiais eficientes. Mudanças no panorama da economia mundial, proporcionadas pelas TICs, com advento das ETs e aumento dos fluxos de IDE, das Relações Contratuais e do comércio intra firma, deslocam o foco de análise da internacionalização do país para a empresa.

O grande apogeu do Investimento Directo Estrangeiro como forma de internacionalização da produção deu-se na segunda metade da década de 1990. O IDE global apresentou um extraordinário crescimento em comparação ao comércio exterior e às relações contratuais. Entre 1996 e 2000 o IDE apresentou um crescimento de $40 \%$ ao ano, enquanto as taxas de crescimento das exportações e das receitas com royalties e licenças foram de 3,7\% e 8,1\% respectivamente (UNCTAD-WIR: 2007). Este crescimento pode ser explicado pela retomada do crescimento da economia mundial em 1993 e o consequente incremento no excedente económico global, já que o IDE apresenta um comportamento

\footnotetext{
${ }^{3}$ Para atender aos objectivos traçados, recorreu-se as estatísticas disponibilizadas pela UNCTAD e pelo Banco Central do Brasil, além do Censo de Capitais Estrangeiros também fornecido pelo BACEN, na expectativa que esses indicassem os fluxos e stocks de IDE no mundo e os destinados ao Brasil no período em análise além de fornecer informações acerca da alteração da principal origem desses investimentos. Nesse sentido, procurou-se demonstrar o aumento da participação absoluta e relativa de Portugal nos investimentos destinados ao Brasil, e a preponderância do processo de fusões e aquisições e, dentro deste contexto, das privatizações.
} 
pró-cíclico, ou seja, acompanha a evolução da economia mundial.

Contudo, quando observamos a forma de ingresso desse investimento, verificamos que ocorreu preponderantemente por fusões e aquisições de empresas já existentes, como se observa no gráfico abaixo, não configurando uma contribuição significativa do ponto de vista do aprofundamento da estrutura industrial, mas sim uma tendência monopolista do sistema económico.

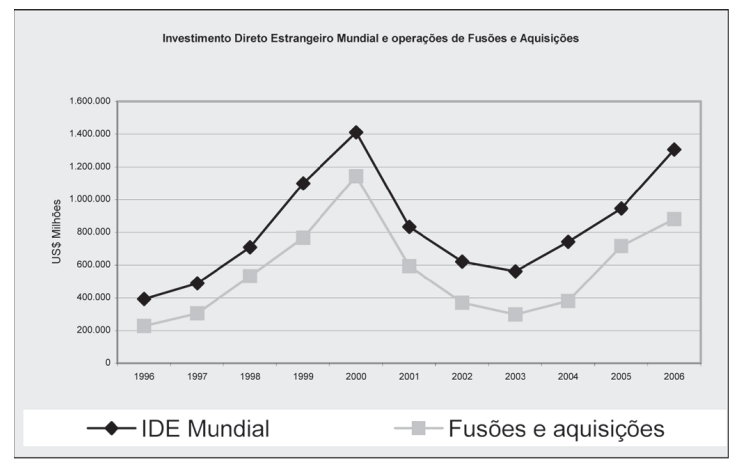

Fonte: UNCTAD

\section{Considerações sobre a economia por- tuguesa e os fluxos de Investimento Directo de Portugal no estrangeiro e no Brasil}

O afastamento de Portugal dos ciclos de inovação tecnológica da Primeira e Segunda Revolução Industrial fez com que, até meados do século Xx, a sua economia se configurasse por uma estrutura industrial composta por bens de baixo valor unitário voltados para o espaço interno, distanciando o país dos restantes da Europa, em níveis tecnológicos. Mesmo o processo de substituição de importações, iniciado nos anos de 1940, era limitado pelo tamanho do espaço interno. Além disso, o peso das colónias em África e na Ásia era significativo para o equilíbrio da Balança de Pagamentos.

Na segunda metade do século Xx, os impulsos externos do ciclo expansivo do pós-guerra e a entrada de Portugal em diversos acordos multilaterais (OCDE em 1948, EFTA em 1960, GATT em 1961 e o acordo preferencial com a CE em 1972) levaram a uma progressiva liberalização comercial e a uma crescente integração económica na Europa, fazendo com que as taxas de crescimento do Produto Interno Bruto chegassem a uma média anual de 6,9\% entre 1960 e 1973 (Guedes: 2001), sendo este processo interrompido com a crise internacional do petróleo em 1973/1974. Concomitantemente, inicia-se um período conturbado que passa pela Guerra Ultramarina e culmina na Revolução dos Cravos, em 25 de Abril de 1974, que pôs fim a ditadura salazarista e determinou o desmonte do império colonial na África. Em 1975, o governo iniciou uma onda de nacionalizações de empresas, notadamente aquelas que actuavam na área financeira (crédito e seguro), electricidade, transportes, petróleo, entre outras. Este processo somente teria fim em 1976 com a aprovação da constituição e as eleições presidenciais. Contudo, as reprivatizações somente se iniciariam em 1983.

Passado esse breve período revolucionário, a opção de integração com a Europa é reafirmada com o ingresso na União Europeia, em 1986, e pelo esforço no cumprimento dos "critérios de convergência", baseados na estabilidade dos preços e dos orçamentos, exigidos no Tratado de Maastricht, em 1992, na passagem para o Euro. Entre 1986 e 2006, Portugal beneficiou de um apoio financeiro dos Estados Comunitários, principalmente para grandes investimentos em infra-estrutura, no sentido de diminuir as disparidades económicas. Contudo, apesar da diminuição das disparidades, com o auxílio da UE e a introdução de novas tecnologias de produção e produto na estrutura industrial, não tem havido, por parte de Portugal, um esforço inovador efectivo. A competitividade das exportações tradicionais portuguesas baseia-se nos baixos custos da força de trabalho em sectores industriais tais como o têxtil, vestuário, calçados de couro, artigos de madeira, mobiliário, cerâmica e vidros, e na dotação de recursos naturais e/ou economias de escala em sectores como fabricação de celulose e papel, refino de petróleo e fabricação de minerais não metálicos, como cimento e, em menor medida, o sector de fabricação de bebidas (Lança: 2000). Recentemente, tem se destacado a fabricação de aparelhos e materiais eléctricos e a fabricação de veículos automotores, sectores com maior valor adicionado. Porém, na sua maioria, fazem parte de estratégias de empresas transnacionais, representando um esforço endógeno incipiente (Guedes: 2001). Essas características evidenciam uma vulnerabilidade da economia portuguesa, visto que está mais focada ainda nos determinantes de vantagem comparativa do que nos determinantes de vantagem competitiva, ou seja, está baseada em produtos de 
baixo valor agregado, na contra mão da tendência mundial de diferenciação do produto via agregação de valor nos países desenvolvidos.

Nesse sentido, por não possuir pontos fortes nem produtos que apresentem diferenciais competitivos que o projecte para o exterior, a opção de internacionalização pelo sector de serviços apresenta-se como a mais adequada para Portugal (Guedes e Olivares: 2003). E o destino desses investimentos direcciona-se para países com uma proximidade espacial, como Espanha, e países com proximidade linguística e cultural, nomeadamente o Brasil, numa lógica muito mais ibérica do que europeia.

Analisando a inserção de Portugal no exterior, observa-se, no decorrer da década de 1990, um significativo aumento do seu Investimento Directo no Estrangeiro (IDPE), o que implicou numa inversão da condição de importador líquido de capital que predominou até então. Assim, observamos que, entre 1996 e 2007, os fluxos acumulados alcançaram a cifra de 115,22 biliões de Euros em valores brutos.

Contudo, nesse período, os investimentos realizados pelas empresas e subsidiárias portuguesas no estrangeiro passam a ter uma dinâmica diferenciada que, além do aumento dos fluxos, passa pela descoberta de novos espaços e sectores. Nesse sentido, sabendo que até 1990 os investimentos no exterior eram canalizados principalmente para a Europa e os EUA, no período de 1991 a 1995 os investimentos portugueses concentraram-se em Espanha e, a partir de 1996, o Brasil torna-se um destino privilegiado para os investimentos directos portugueses, em especial devido ao processo de privatizações, mas também pela identidade cultural comum. A partir de 2000, a Holanda passa a figurar como principal destino dos investimentos directos portugueses e a Dinamarca é incluída no primeiro escalão desses mesmos investimentos a partir de 2003.

Analisando os valores brutos, podemos concluir que, no período de 1996 a 2007, os investimentos em Espanha possuem uma sensível preponderância sobre os investimentos no Brasil. Contudo, verificando os valores líquidos, ou seja, a diferença entre o investimento e o desinvestimento, observa-se que o Brasil caracteriza um espaço preferencial, em detrimento dos investimentos portugueses nos outros países europeus, à excepção da Holanda, que representa o primeiro destino tanto em valores brutos como líquidos ${ }^{4}$.

\section{Fluxo total de IDE de Portugal no exterior entre 1996 e 2007 \\ Por país de destino (Milhares de Euros)}

\begin{tabular}{|l|c|l|c|}
\hline País de destino & Valores brutos & País de destino & Valores líquidos \\
\hline Holanda & 29127029 & Holanda & 12755052 \\
Espanha & 19043920 & Brasil & 8387324 \\
Brasil & 17913843 & Espanha & 6545381 \\
Dinamarca & 5965121 & Dinamarca & 2964933 \\
Irlanda & 3521081 & Reino Unido & 1608294 \\
Reino Unido & 2733820 & Irlanda & 1418242 \\
EUA & 1915576 & EUA & 1386146 \\
Polónia & 1556451 & Polónia & 1157729 \\
Bélgica & & Bélgica & \\
e Luxemburgo & 1491600 & e Luxemburgo & 630288 \\
França & 1432585 & França & 370107 \\
Grécia & 1263908 & & \\
Outros & 24394884 & Outros & 9.646 .848 \\
Todos os Países & 115.854 .889 & Todos os Países & 48.301 .218 \\
\hline
\end{tabular}

Fonte: Banco de Portugal

Em relação à forma de entrada dos investimentos portugueses no exterior, observa-se, em todos os anos, excepto em 1998 e 1999, uma preponderância do capital investido directamente nas empresas, sob a forma de aquisição, aumento de participação ou constituição de empresas, que representou 5,82 biliões de Euros em 2007. Verifica-se ainda uma relevância dos lucros reinvestidos, que alcançou aproximadamente 1,71 bilhão de Euros tanto em 2006 quanto em 2007, e de outros capitais, compostos em sua maioria por empréstimos inter companhias e que alcançaram 4,8 biliões de Euros em 2007. Contudo, deve-se levar em consideração que "frequentemente, o investimento directo no exterior dos grupos portugueses é realizado através das SGPS (Sociedades Gestoras de Participações Sociais ${ }^{5}$ ) dos grupos, o que se traduz na contabilização dos movimentos de capitais, de acordo com a CAE-Rev. 2, no subsector dos Serviços, 'Outras Actividades de Serviços Prestados Principalmente às Empresas, quando a verdadeira origem sectorial dos fundos corresponde, nomeadamente, aos

\footnotetext{
${ }^{4}$ É importante salientar, que apesar de apresentar valores modestos, observa-se nos últimos anos um interesse das empresas portuguesas pelos Países Africanos de Língua Oficial Portuguesa (PALOP), verificando-se um fluxo acumulado de 1,76 biliões de Euros em valores brutos entre 2001 e 2007 , sendo que Angola foi o destino de 74\% deste valor, estando este incremento ligado ao fim da guerra civil em Angola em 2002. Ver tabela em anexo.

5 Conhecidas pelo termo holdings, as SGPS são criadas com o objectivo de administrar um conglomerado de empresas de ramos económicos semelhantes ou distintos, possuindo a totalidade ou parte das acções das empresas do grupo. Sendo esta uma forma indirecta de desenvolver uma ou mais actividades económicas, as grandes empresas portuguesas, seguindo uma tendência mundial, têm optado por constituir uma SGPS para administrar todas as suas participações sociais e suas subsidiárias no exterior. Como o investimento directo dirigido ao estrangeiro é realizado em sua maioria pelas SGPS que, por sua vez, são classificadas como "Outras Actividades de Serviços Prestados Principalmente às Empresas", a verdadeira destinação dos investimentos, para sectores como indústria, produção de energia e telecomunicações, não é contabilizada. É importante ressaltar contudo, que as SGPS das instituições financeiras, de acordo com a CAE - Rev. 2, são classificadas no próprio sector das actividades financeiras.
} 
sectores da 'Indústria, 'Produção, Distribuição de Electricidade e Água, 'Transportes e Comunicações, entre outros" (Claro \& Escária, 2003: 92).

\section{O IDE na economia brasileira e seus novos determinantes}

Os agentes económicos possuem activos em sua propriedade que lhe garantem uma vantagem competitiva no sistema económico mundial. Este activo pode ser a tecnologia de produção (técnica de produção) e de produto (diferenciação do produto), capacidade de gestão, organizacional e espaçológica e a capacidade de mobilização do capital. Nesse sentido, na nova lógica do princípio da internacionalização da produção, que engloba comércio exterior, investimento directo e relações contratuais, o foco passa a ser a firma e a determinação do activo, ou activos, que lhe assegurem uma vantagem competitiva perante os concorrentes. Esses activos específicos permitem à empresa obter lucro anormal no sistema económico internacional, e é precisamente a expectativa do lucro anormal que leva as empresas a realizar operações internacionais (Gonçalves: 2005).

Analisando os activos que lhe geram vantagem competitiva, e também os custos e benefícios, os riscos e incertezas inerentes a cada tipo de internacionalização da produção é que a empresa poderá escolher entre relações contratuais, comércio exterior e IDE. O comércio exterior e o investimento directo possuem custos inerentes à montagem de uma estrutura burocrática de tomada de decisão, supervisão e gestão de operações internacionais. Já os custos das relações contratuais são aumentados se existe risco ou incerteza da tecnologia "vazar" e a empresa perder sua vantagem competitiva.

Para a escolha do IDE como forma de internacionalização, os factores de localização de cada país são fundamentais. O tamanho do espaço interno, a estabilidade da taxa de câmbio (determinante tanto para a entrada quanto para a saída do capital), a estabilidade nas regras do jogo e a não-discriminação aos investimentos estrangeiros são os principais determinantes. Outros factores considerados são a dotação e os preços dos factores de produção (salários, juros e alugueres), a tributação, o nível de inflação, o nível de actividades (PIB), a infra-estrutura (estradas, energia, telecomunicações, portos e aeroportos), entre outros.
O investimento directo estrangeiro (IDE) no Brasil apresentou um expressivo aumento a partir de meados da década de 1990, alcançando a cifra recorde de aproximadamente US $\$ 32,8$ biliões em 2000. Este aumento dos fluxos e, consequentemente, do stock de IDE pode ser explicado por factores externos e internos. No âmbito externo, a aceleração do processo de globalização proporcionado pelas TICs, a nova dinâmica do espaço financeiro, o aumento da liquidez internacional e a expansão das ETs, exerceram forte impacto sobre os níveis de crescimento dos investimentos directos globais e, consequentemente, influenciaram o IDE brasileiro, que segue essa tendência mundial como se observa no gráfico seguinte.

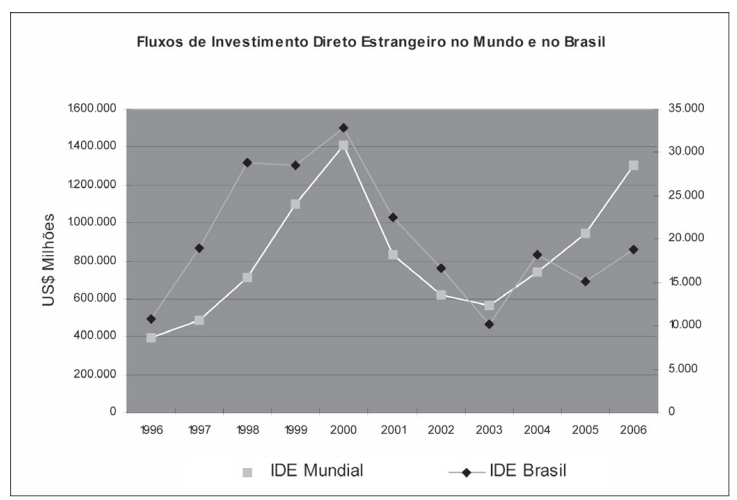

Fonte: Banco Central do Brasil e UNCTAD

No contexto interno, as políticas macroeconómicas de controlo inflacionário implementadas pelo Plano Real no governo Itamar Franco em 1994, que abrangiam a abertura comercial e garantiram a estabilidade económica naquele período, tiveram forte influência nos fluxos de IDE. A onda internacional de fusões e aquisições, tanto de empresas privadas como públicas, verificou-se também no Brasil, sendo responsável por grande parte dos ingressos de IDE no país. Os processos de fusões e aquisições de empresas privadas nacionais por parte de corporações estrangeiras, são resultado da fragilidade económica e financeira dessas empresas diante da abertura económica brasileira e tornada possível com o auxilio das políticas fiscais e monetárias, que visavam combater a inflação, mas que acabaram por provocar o encarecimento do crédito e a redução dos investimentos. No caso brasileiro, o que explica a relativa manutenção dos investimentos num patamar razoável, foi a actuação do Banco Nacional de Desenvolvimento Económico e Social (BNDES). Este banco de fomento, criado em 1952 
no governo de Getúlio Vargas, cobra juros levemente positivos para os grandes projectos de investimento, tendo passado nos anos noventa a financiar as ET's, inclusive para compra de empresas privadas e estatais no Brasil (sic).

Os processos de privatização de empresas públicas, inseridos na contabilidade das fusões e aquisições, auxiliaram na sustentação dos fluxos até 2000, como vemos no gráfico seguinte. Além de caracterizarem uma maior abertura da economia para o exterior, os fluxos de investimento estrangeiro no Brasil tinham a característica de serem contínuos, já que não foram significativamente afectados pelas crises ocorridas na viragem do século (a crise cambial brasileira em 1999, a argentina em 2001/2002 e a sucessão presidencial em 2002) (Silva \& Fernandes: 2003).

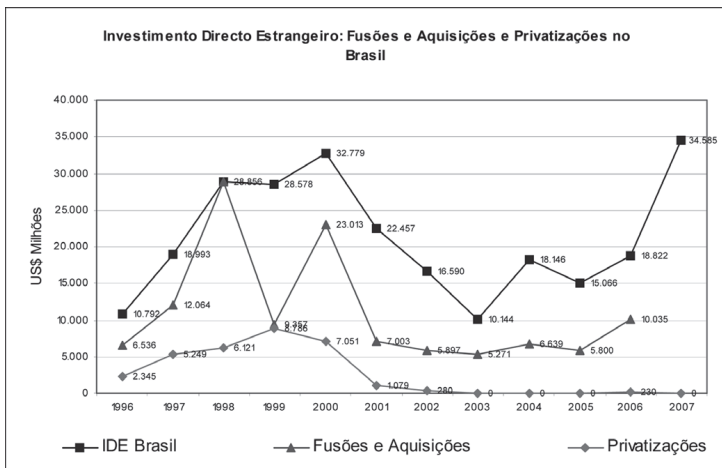

Fonte: Banco Central do Brasil e UNCTAD

Analisando especificamente os fluxos do investimento directo de Portugal no Brasil, todos estes factores estão presentes e observa-se no gráfico abaixo que, em 1996, o valor bruto desses investimentos foi de 290 milhões de Euros, em 1998 atinge o ápice de 4,3 biliões de Euros, e em 2003 o mínimo de 194 milhões de Euros, alcançando aproximadamente 567 milhões de Euros em 2007. Verifica-se também que, entre 1996 e 2007, os fluxos acumulados atingem 17,9 biliões de Euros. O forte fluxo em 1998 é explicado pelo grande volume de negociações de empresas estatais no processo de privatizações, principalmente a aquisição da Telesp pela Portugal Telecom, em conjunto com a espanhola Telefónica, e a queda do fluxo, observada desde o início da década de 2000, segue uma tendência de redução do investimento directo a nível mundial.

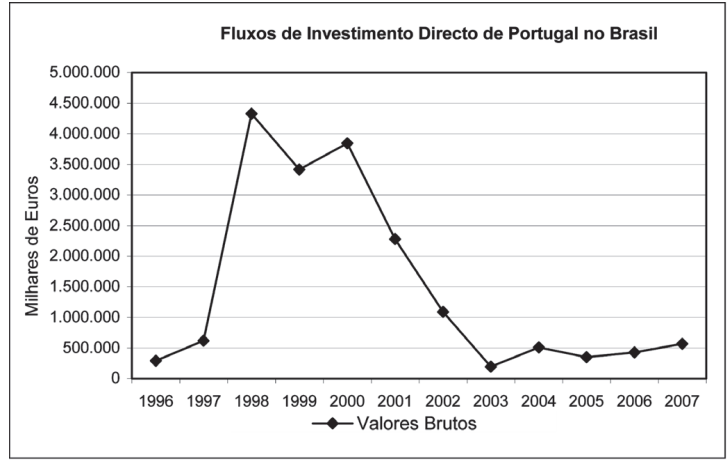

Fonte: Banco de Portugal

De acordo com o Banco de Dados do Observatório dos Investimentos Portugueses no Brasil, composto por dados de 240 empresas, a maioria das empresas portuguesas se internacionalizou no Brasil entre 1996 e 1999, o que evidencia a importância do processo de privatizações. Observava-se ainda que, em 2003, 68\% das 240 empresas possuíam sede em Lisboa ou no Porto, centros económicos do país, caracterizando-se ainda como grandes empresas, como a Portugal Telecom, nas telecomunicações, a $E D P$, na distribuição de energia, mas também em projectos de construção de barragens, e a CIMPOR, na indústria do cimento. Evidenciava-se também que os investimentos das empresas se direccionam principalmente para as regiões sudeste e sul do Brasil, talvez devido à similaridade "da dispersão territorial no país de origem e no destino" (Silva \& Fernandes, 2003: 118) ${ }^{6}$.

Com relação ao número de empresas por sectores de actividades, observava-se que $59 \%$ das empresas portuguesas no Brasil eram do sector industrial. Contudo, quando se observava o volume de negócios por sectores de actividades, verificava-se uma preponderância das actividades comerciais, que representam $38 \%$ do total de volume de negócios, seguido dos serviços, com $26 \%$, e a produção e distribuição de electricidade, gás e água, com 14\%. Tal facto indica "um volume de negócios por

\footnotetext{
${ }^{6}$ Contudo, se analisamos a evolução dos investimentos directos líquidos em relação aos investimentos brutos, verificamos um descolamento a partir de 1999, que, apesar de ter se tornado menos intenso nos últimos anos foi suficiente para apresentar investimento líquido negativo, ou seja, desinvestimento em 2002, 2003 e 2005.

Apesar dos dados serem insuficientemente actualizados, acredita-se que esta configuração empresarial, tanto em Portugal como no Brasil, não tenha se alterado significativamente, excepto pela saída da SONAE da área supermercadista em 2005, que possivelmente alterou a configuração das actividades económicas por volume de negócios, visto a importância desta empresa para o sector de comércio.
} 
empresa muito mais baixo na indústria do que nos restantes sectores considerados" (Silva \& Fernandes, 2003: 111).

As informações relacionadas com a participação de empresas portuguesas no tecido empresarial brasileiro, analisadas a partir do ranking das mil maiores empresas por receita líquida auferida em 2007 na revista Valor 1000 (2008), apresenta resultados que ilustram o que estamos afirmando: são seis grupos portugueses presentes no ranking, mas o peso relativo da Portugal Telecom é predominante neste grupo, representando $60,4 \%$ do total das receitas. Considerando a segunda e a terceira posições (EDP e Brisa), o percentual das receitas atinge 93,2\%. Entre estes grandes grupos, o segmento dos serviços é amplamente dominante; apenas a Sonae e a Cimpor tem presença na indústria de transformação. Em relação à forma de ingresso, apenas a Tafisa (Sonae) iniciou um novo empreendimento, tendo a PT e EDP ingressado pelas privatizações e as demais pelo processo de fusões e aquisições (dos Santos: 2008).

O crescimento do IDE a partir de 2003, incluindo o recorde histórico de aproximadamente US\$ 34,6 biliões alcançado em 2007, ainda é influenciado pelas fusões e aquisições e garantido pela estabilidade económica, mas possui novos determinantes, como a redução na taxa de juros, o espaço interno aquecido e os lucros crescentes auferidos pelas empresas estrangeiras instaladas no país. Visto que a remessa de lucros de investimento directo tem apresentado uma trajectória ascendente, como podemos reparar no gráfico que se segue, o que, por sua vez, torna-se um atractivo para novos investimentos.

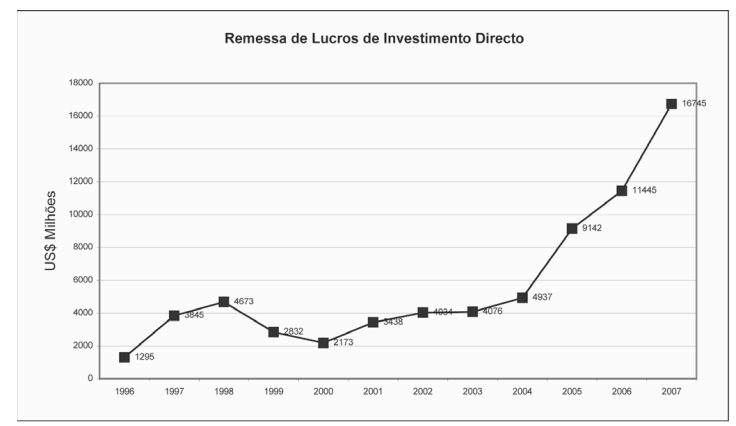

Fonte: Banco Central do Brasil
Do ponto de vista geográfico, apesar da manutenção dos EUA como maior investidor, podemos observar, tanto pelos stocks quanto pelos fluxos acumulados de investimento directo por país de origem, um aumento da participação de países que, antes de 1995, possuíam presença quase nula no IDE direccionado para o Brasil, como Espanha e Portugal, ao passo que tradicionais investidores, como Alemanha, Suíça, Japão e Reino Unido, diminuíram sensivelmente seus investimentos, visto que tiveram participação reduzida no processo de privatizações (Tabela 1 em anexo).

Esse aumento de participação, tanto absoluto quanto relativo, de Espanha e Portugal, pode ser verificado pelos fluxos acumulados, de 1996 a 2007, onde Espanha é responsável por 12,42\% do IDE para o Brasil, enquanto Portugal responde por $4,78 \%$ deste montante.

Contudo, se analisarmos isoladamente o total de fluxos de 2001 a 2007, veremos que tanto Espanha como Portugal têm diminuído a sua participação relativa nos investimentos directos, pelo que se pode pensar que o ciclo dos grandes investimentos de empresas portuguesas se esgotou ou continuará se os incentivos forem mais favoráveis. Destaca-se, também, a ascensão da Holanda como grande investidor neste início do século, superando os EUA em fluxos e, ainda, a actuação de países como México, Austrália, Chile, Noruega e Dinamarca que aumentaram consideravelmente seus investimentos directos no Brasil a partir de 2005.

\section{Considerações finais}

No final dos anos cinquenta do século passado a economia portuguesa iniciou um caminho de abertura aos fluxos de comércio e investimento na Europa, acompanhado por uma nova onda de imigração, desta vez voltada para o continente, especialmente para França. As variáveis internas e externas conjugadas pelo ciclo expansivo do pós guerra, estenderam-se até 1973. Com o 25 de Abril, entre outros processos, a descolonização devolveu Portugal à sua dimensão territorial europeia de 500 anos atrás. A inserção na então Comunidade Europeia é consolidada com o ingresso formal em 1 de Janeiro de 1986, juntamente com Espanha. A partir daí, as economias ibéricas iniciam um intenso processo de integração no contexto da construção europeia. Os anos noventa marcam a continuidade 
e o aprofundamento desta integração num patamar mais elevado representado pela internacionalização via IDE, onde os segmentos das telecomunicações e das energias estão articulados estrategicamente. A opção preferencial é dirigida a um espaço cultural e linguístico com passado comum, a Iberoamérica, com a quase totalidade dos investimentos voltados para o Brasil, no caso das empresas portuguesas. Para além da condição de exportadoras líquidas de capital, ambas as economias ibéricas tornam-se também receptoras de contingentes de trabalhadores do estrangeiro, passando a ser países de imigrantes, ao contrário dos últimos séculos, onde a emigração marcou as nações da Península Ibérica.

De uma forma mais esquemática, podemos enfatizar alguns pontos referentes ao processo de internacionalização e aos novos espaços do investimento português no Brasil:

1. O Relatório sobre investimento mundial da UNCTAD (WIR: 2008) confirma o Brasil como a quarta posição entre os destinos preferidos do investimento estrangeiro em 2007, onde as demais posições e valores são os seguintes: China, US $\$ 58200 \mathrm{mi}-$ lhões; Índia, US $\$ 43000$ milhões; EUA, US $\$ 38000$ milhões; Brasil, US $\$ 34600$ milhões e a Federação Russa, com US $\$ 29900$ milhões. Além disso, o Brasil e a Federação Russa são apontados como os países mais atractivos para o investimento estrangeiro, sendo os dois mais citados pelas empresas que responderam à pesquisa. Estas informações, apesar do quadro de instabilidade e abrandamento da economia internacional, confirmam o potencial de expansão do IDE na economia brasileira que, além da própria dimensão, é considerada no Relatório como porta de entrada para outros espaços da América Latina, o que em nossa perspectiva está relacionado com as políticas de integração regional em curso.

2. Os investimentos portugueses no Brasil tiveram inicialmente uma natureza característica da época da globalização, muito ligada à compra de empresas em sectores tradicionalmente geridos pelo Estado, mas com o tempo adquiriram uma dinâmica sectorial mais ampla, caracterizando-se pela continuidade dos fluxos e uma razoável estabilidade, o que se verifica na hotelaria, logística e manutenção de estradas, aluguer de automóveis, petróleo, cimento, ou seja, vieram para ficar e têm possibilidades de crescimento.

3. O perfil dos investimentos é o resultado das características de competitividade da economia portuguesa: serviços produtivos, finanças, comércio, restauração e turismo, cimento, o que tem permitido uma certa estabilidade dos fluxos e perspectivas de expansão. No horizonte de crescimento do IDE para o Brasil, o grande espaço a ser preenchido é o das infra-estruturas, (transportes e energia, principalmente), que possuem carências acentuadas, e o imobiliário, com destaque para a hotelaria. Portanto, o sector dos serviços continuará a ser o principal destino para os investidores externos, de uma forma geral, e para os portugueses, em particular.

4. Os investimentos portugueses inscrevem-se numa lógica ibérica, ocupando um espaço caracterizado pelas afinidades linguística, culturais e afectiva, o que permite um dialogo fluido, incluindo o plano político, especialmente no espaço ibero-americano (9,2\% da população e $9,8 \%$ do produto interno bruto mundiais pela paridade do poder de compra), onde o Brasil tem um peso significativo - $31,5 \%$ da população e $27,5 \%$ do produto interno bruto pela paridade do poder de compra no espaço ibero-americano (Cepal e Segib: 2006).

5. A percepção mais favorável dos investimentos portugueses e do IDE, em geral, por parte dos países na América Latina, resulta de uma visão diferente sobre o desenvolvimento, onde o investimento estrangeiro é visto como uma alavanca ao processo de crescimento económico, enquadrando-se num modelo de abertura comercial e financeira ao exterior, de incentivo às exportações, de reconstrução das redes de infra-estruturas e modernização económica e tecnológica, implicando em ganhos sistémicos.

6. Embora não tenha sido objecto do artigo, merece destaque o recente incremento do investimento de empresas brasileiras em Portugal, como é o caso da Marcopolo, 
fabricante de carroçarias de autocarros, com uma unidade em Coimbra e capacidade para fabricar anualmente 230 unidades e que são, em sua maior parte, exportadas para a Europa. Outra empresa de destaque é a Embraer, que em 2004 liderou um consórcio e comprou num processo de privatização a OGMA (Oficinas Gerais de Material Aeronáutico) e em Julho de 2008 anunciou investimentos para a construção de duas novas fábricas localizadas em Évora. Por fim, a Petrobrás, líder mundial na prospecção em águas profundas, anunciou uma parceria com a Galp Energia e a Partex, num acordo para produção de petróleo em quatro blocos da Bacia de Lusitânia, ao norte de Lisboa.

7. A partir dos anos 90 o IDE português criou um novo espaço de valorização, cuja lógica e dinâmica foi iniciada pelo IDE espanhol na América Latina poucos anos antes. No caso português, estes investimentos estão mais centrados no Brasil.
8. À crescente integração das economias ibéricas no espaço europeu (comércio e investimento) desde 1986, quando ambas as economias ingressam na União Europeia, corresponde a articulação de capitais ibéricos. Exactamente 10 anos após o ingresso na UE, o IDE português inicia um agressivo processo de internacionalização no Brasil, articulado com os espanhóis justamente nos dois segmentos em que estão as suas principais empresas: telecomunicações e energia (Portugal Telecom e EDP).

9. A nossa perspectiva é de que a expansão do IDE ibérico na América Latina reedita o processo de integração em curso entre as duas economias desde o ingresso de Portugal e Espanha na UE em 1986. Além do aspecto quantitativo, onde o IDE ibérico se constitui no maior investidor europeu e tem a segunda posição no Brasil desde 1996, abaixo apenas dos EUA, é também neste sentido mais soft que afirmamos que o Cone Sul é uma realidade mais ibérica do que europeia. 


\section{Referências Bibliográficas}

CEPAL e SEGIB (Secretaria Geral Ibero-Americana). Espaços Ibero-Americanos. Santiago: Cepal, 2006.

COMITE DE L'INVESTISSEMENT INTERNATIONAL ET DES ENTREPRISES MULTINATIONALES. Definition de Reference de l'OCDE pour les Investissements Directs Internationaux. Paris: OCDE, 1995.

DEPARTAMENTO DE PROSPECTIVA E PLANEAMENTO. Prospectiva e Planeamento. O investimento português no estrangeiro - Brasil. Volume 9. Lisboa: 2003.

Dos SANTOS, L. A. C. O Investimento Direto de Portugal no Brasil: Uma análise do período pós 1996. Relatório Final de Pesquisa de Iniciação Científica, realizada na UFRRJ com orientação do Professor Cezar Guedes e bolsa concedida pela FAPERJ, através de selecção pública. Seropédica: UFRRJ, 2008.

DUNNING, J. H., "Trade, location of economic activity and the multinational enterprise: a search for an eclectic approach". In: OHLIN, B. The international allocation of economic activity. London: Macmillan, 1977.

GONÇALVES, R., Economia Política Internacional: Fundamentos Teóricos e as Relações Internacionais do Brasil. Rio de Janeiro: Campus, 2005.

GUEDES, C. A. M. Migrations of capitals, the return of the Caravelas to Brasil. Artigo apresentado na Conferencia da Society for Latin American Studies (SLAS), realizada na Universidade de Derby (Inglaterra) de 8 a 10 de Abril de 2005.

"Competitividade e inserção internacional: Algumas observações sobre a economia portuguesa". In: Perspectiva Econômica, Vol. 36, n. 114. São Leopoldo, Unisinos, Abril/ Junho 2001.

GUEDES, C. A. M. e OLIVARES, M. G., "Investimento português no Brasil: os desafios de uma lógica ibérica". In: Cadernos de economia $\mathrm{n}^{\circ}$ 62. Lisboa, Ordem dos Economistas Portugueses, 2003 (b).

GUEDES, C. A. M. e CARDOSO, S. R., "Emprego e Inovações Tecnológicas no Pensamento Económico". In: Emprego e Desenvolvimento Tecnológico: Artigos dos Pesquisadores. DIEESE/ CESIT (Orgs.). São Paulo: 1999

INSTITUTO NACIONAL DE ESTATÍSTICA, Classificação Portuguesa das Actividades Económicas: CAE - rev. 2.1. Lisboa: INE, 2003.
LANCA, I. S. "Especialização Internacional e Competitividade em Portugal (1970-1996)". In: LANÇA, I. S. (Org.) A Indústria Portuguesa - Especialização Internacional e Competitividade. Oeiras: Celta, 2000.

NACIONALIZAÇÕES 1975. In: Infopédia. Porto: Porto Editora 2003-2008. Disponível na www: <URL: http://www.infopedia. pt/\$nacionalizacoes-1975>. Acesso em: 23 jul. 2008.

OLIVARES, M. G. e GUEDES, C. A. M., "O investimento das grandes empresas ibéricas na América Latina”. In: Bahia Análise \& Dados. Volume 13, $\mathrm{n}^{\circ}$ 1. Salvador: Superintendência de Estudos Econômicos e Sociais da Bahia, Junho de 2003.

OLIVEIRA, D. R. de, A anatomia do Investimento Direto Estrangeiro - IDE - nos anos 90: o caso brasileiro. Relatório final de pesquisa de Iniciação Científica realizada no âmbito do Convênio UFRRJ/CNPq, orientada por Cezar Guedes. Seropédica, UFRRJ, 2004

SILVA, C. L. da, Investimento Estrangeiro Direto: da dependência à globalização. Rio de Janeiro: Fundo de Cultura, 2005.

SELA, Inversiones extranjeras directas (IED) en América Latina y el Caribe,(SP/CL/XXVIII.O/Di N. ${ }^{\circ} 3$ - 02) XXVIII Reunión Ordinaria del Consejo Latinoamericano, Caracas, Venezuela, 11-13 de diciembre de 2002

SILVA, J. R.; COSTA, C. G.; FERNANDES, F. R. C., "A Internacionalização das Empresas Portuguesas: A presença no Brasil, primeiras investigações". In: XII Jornadas Luso-Espanholas de Gestão Científica. Covilhã: Departamento de Gestão e Economia / Universidade da Beira Interior, Abril 2002.

VASCONCELLOS, M. A. S. e LOPES, L. M., $M a-$ nual de Macroeconomia - Básico e Intermediário. São Paulo: Atlas, 2000. $2^{\circ}$ ed.

UNITED NATIONS CONFERENCE ON TRADE AND DEVELOPMENT (UNCTAD). World Investiment Report. New York and Geneva: United Nations, 2007 e 2008.

VALOR ECONÔMICO. Valor 1000 Maiores Empresas n. ${ }^{\circ} 8$. Rio de Janeiro: 2008. 


\section{Anexos}

\begin{tabular}{|lrr|}
\hline \multicolumn{3}{|l|}{ Fluxo total de IDE para Brasil } \\
$\mathbf{1 9 9 6}$ a 2007. US $\$$ Milhões \\
Países de origem & US\$ Milhões & \\
Estados Unidos & 53093,62 & 20,89 \\
Países Baixos (Holanda) & 38 883,19 & 15,30 \\
Espanha & 31564,28 & 12,42 \\
Caimão, Ilhas & 21392,68 & 8,42 \\
França & 16358,71 & 6,44 \\
Portugal & 12148,45 & 4,78 \\
Alemanha & 8528,59 & 3,36 \\
Luxemburgo & 7802,42 & 3,07 \\
Canadá & 6780,47 & 2,67 \\
Japão & 6304,89 & 2,48 \\
Bermudas & 5847,64 & 2,30 \\
Suíça & 5178,81 & 2,04 \\
Reino Unido & 5036,62 & 1,98 \\
Virgens, Ilhas & 4224,32 & 1,66 \\
Itália & 3991,64 & 1,57 \\
Bélgica & 2869,07 & 1,13 \\
Panamá & 2868,81 & 1,13 \\
Bahamas, Ilhas & 2203,99 & 0,87 \\
Suécia & 2080,04 & 0,82 \\
Uruguai & 1802,98 & 0,71 \\
Argentina & 1140,92 & 0,45 \\
Outros & 14038,85 & 5,52 \\
Total & 254141,00 & 100,00 \\
\hline
\end{tabular}

Fonte: Banco Central do Brasil

Cotação do último dia útil de cada período. 


\begin{tabular}{|c|c|c|c|}
\hline \multicolumn{4}{|c|}{ Os maiores grupos portugueses no Brasil em 2007} \\
\hline & Empresas & $\begin{array}{c}\text { Colocaçãa } \\
\text { Valor } 1000\end{array}$ & \begin{tabular}{||c|} 
Receita Líquida \\
em milhões de $\mathrm{R} \$$
\end{tabular} \\
\hline $1^{o}$ & $\begin{array}{c}\text { Portugal Telecom SGPS } \\
\text { VIVO } \\
\text { UOL }\end{array}$ & $\begin{array}{l}14^{\circ} \\
479^{\circ}\end{array}$ & $\begin{array}{c}12492,50 \\
501,8\end{array}$ \\
\hline $2^{\mathrm{o}}$ & $\begin{array}{l}\text { EDP SGPS } \\
\text { Bandeirante Energia } \\
\text { Escelsa } \\
\text { Enersul } \\
\text { Enerte } \\
\text { Enerpeixe }\end{array}$ & $\begin{array}{l}133^{\circ} \\
212^{\circ} \\
365^{\circ} \\
407^{\circ} \\
730^{\circ}\end{array}$ & $\begin{array}{l}1993,10 \\
1229,50 \\
693,2 \\
618 \\
310,1\end{array}$ \\
\hline $3^{\circ}$ & $\begin{array}{l}\text { BRISA SGPS } \\
\text { Autoban } \\
\text { Novadutra } \\
\text { Via Oeste } \\
\text { Rodonorte }\end{array}$ & $\begin{array}{l}280^{\circ} \\
405^{\circ} \\
605^{\circ} \\
840^{\circ}\end{array}$ & $\begin{array}{l}923,4 \\
618,5 \\
384,5 \\
265,3\end{array}$ \\
\hline $4^{\mathrm{o}}$ & $\begin{array}{l}\text { CIMPOR SGPS } \\
\text { Cimpor Cimentos do Brasil }\end{array}$ & $298^{\circ}$ & 857,9 \\
\hline $5^{\circ}$ & $\begin{array}{c}\text { SONAE SGPS } \\
\text { Tafisa }\end{array}$ & $589^{\circ}$ & 394,2 \\
\hline $6^{\circ}$ & $\begin{array}{l}\text { SAG SGPS } \\
\text { Unidas }\end{array}$ & $975^{\circ}$ & 215,3 \\
\hline
\end{tabular}

Fonte: Valor Económico, 2008 